\title{
Mechanical and Morphological Properties of LDPE/ PHB Blends Filled with Castor Oil Pressed Cake
}

\author{
Gustavo A. D. Burlein, Marisa C. G. Rocha* \\ Instituto Politécnico, Universidade do Estado do Rio de Janeiro - UERJ, \\ CP 97282, CEP 28601-970, Nova Friburgo, RJ, Brazil
}

Received: December 21, 2012; Revised: November 7, 2013

\begin{abstract}
Blends of PHB and LDPE were prepared by melt mixing in a twin screw extruder. Castor oil cake (CC) was used as filler for the blends. The design of experiments (DOE) technique was used to evaluate the effect of the components proportion on the materials properties. The mechanical properties and morphology of the materials were evaluated. The LDPE Young's modulus increases but the other tensile properties and impact resistance deteriorate with the addition of $\mathrm{PHB}$ or CC. The tensile strength values of binary mixtures of LDPE lie in the range from 8.9 to $10 \mathrm{MPa}$. As some commercial grades of LDPE have mechanical strength in this range, it may be inferred that the addition of a certain amount of PHB or CC to LDPE may be considered as a possibility for obtaining LDPE based materials with increased susceptibility to biodegradation. The poor interfacial adhesion between the phases became visible in all samples.
\end{abstract}

Keywords: low density polyethylene, castor oil pressed cake, poly (3-hydroxybutyrate), mechanical properties, mixture design of experiments

\section{Introduction}

Nowadays, there is a great concern about the increasing volume of plastic waste generated in the world, especially in great urban centers. In this scenario, numerous studies have been conducted in order to: (1) Enhance the biodegradability of fossil-fuel-based conventional polymers by blending them with biodegradable natural polymers such as starch or cellulose; (2) Mixing with pro-oxidants so that they are more easily degraded; and (3) Isolate and improve microorganisms that can efficiently degrade these polymers ${ }^{1-4}$.

Polyolefins are considered bioinert polymers which mean that they are highly resistant to assimilation by microorganisms such as fungi and bacteria. This is expected as the long hydrocarbon chains of these polymers are responsible by the pronounced hydrophobic character. Besides, the addition of antioxidants and stabilizers during their manufacture keeps these materials from atmospheric oxidation. Other structural characteristics such as high molecular weight, high packing density and low surface area make polyolefins non susceptible to biodegradation ${ }^{4-7}$.

There is no single definition of biodegradation. Until few years ago, biodegradation was perceived as a natural process that occurs solely by the action of microorganisms leading to the recycling of carbon, the mineralization of organic compounds and the generation of new biomass. At present, according to some researchers ${ }^{8,9}$, when the complexity of biodegradation of polymeric materials is better understood, this process is defined considering that it results from combination of biotic and abiotic factors which act synergistically to decompose organic matter.

According to Lucas et al. ${ }^{8}$, biodegradation is considered to take place throughout three stages: biodeterioration;

*e-mail: mrocha@iprj.uerj.br biofragmentation; and assimilation, without neglect the participation of abiotic factors. Besides, the process can stop at each stage.

Biodeterioration is mainly the result of the activity of microorganisms, growing on the surface and/or inside a given material. It is important to emphasize that microorganisms may act by mechanical, chemical and enzymatic means. The biodeterioration of thermoplastic polymers may proceed by two different mechanisms, named bulk and surface erosion ${ }^{8}$.

Biofragmentation involves the cleavage of the long polymer chains due to the mixed action of abiotic factors and microbial communities, which secretes enzymes or generates free radicals. A polymer is considered as fragmented when low molecular weight molecules are found within the media. After being transported into the cytoplasm, the small molecules integrate the metabolism pathways. This step is called assimilation and is essential to produce microbial energy, biomass and metabolites. Assimilation allows microorganisms to growth and to reproduce while consuming substrate from the environment ${ }^{8,9}$.

Low density polyethylene (LDPE) plays a key role in the industry of polyolefins due to its wide range of applications. This polymer has good properties, such as: high flexibility, good processability; excellent resistance to dilute and concentrated acids, alcohols, bases and esters; impact resistance; and dimensional stability ${ }^{10}$. Nevertheless, LDPE waste persists for thousands years after disposal causing a negative environmental impact. Therefore, the introduction of biodegradable polymers or natural fillers in LDPE based materials formulation may be considered as an alternative in the development of more ecofriendly material ${ }^{9,11}$. 
The high molecular weight of polyethylene represents a serious problem for its biodegradation, as a molecule of such size cannot cross a cell wall and a cytoplasmatic membrane of the microbial cells. Therefore, it is necessary to reduce its molecular weight by some pretreatments, such as: photo-oxidation; thermo-oxidation; and chemical oxidation. The sensitivity of polyolefins towards thermal oxidation is largely due to the presence of impurities, hydroperoxydes and carbonyl groups ${ }^{8,9}$. Shear degradation can also generate free radicals which attack the molecular structure of polyolefins.

Abiotic factors also seem to accelerate the biodegradation behavior of polyethylene. Results published in the literature $^{12}$ have indicated that environmental factors like sun-light, temperature and rainfall may enhance the rate of biodegradation of the polymer in nature.

Other possible processes to accelerate biodegradation rate of polyethylene in the environment is copolymerization, blending or grafting with functional polymers and compounds. It has been reported that the addition of additives having hydrophilic groups makes polyolefin less hydrophobic and susceptible to photochemical, chemical and microbial degradation. The microbial assimilation of the filler, serving as initial point of microbial attack, results in the increase of the surface area of the synthetic material rendering it more susceptible not only to biotic but also to abiotic oxidation. Biodegradable polymers, such as starch and poly (3-hydroxybutirate) (PHB) also have been used as degradable fillers in polyethylene based materials $s^{8,9,13}$.

Incorporation of starch in LDPE was previously reported to impart biodegradability to LDPE/starch blends and resulted in commercial application of LDPE/starch blend (90/10) which was reported as being biodegradable. This process involved the addition of an auto-oxidant such as corn oil that shortens the degradation period. Further this technology was improved ${ }^{2,14}$.

Poly (3-hydroxybutyrate) is aliphatic polyester produced by several microorganisms that presents very good mechanical properties. However, application of this polymer is limited due to its high production cost and some properties, such as: high brittleness. Therefore, blending of PHB with suitable polymers may offer the opportunity to obtain cheaper products with improved mechanical properties $^{15-21}$. Besides, blending conventional polyolefins with PHB has been considered an alternative to minimize the disposal problem in landfills and improve the instrinsic britlleness that restricts PHB applications ${ }^{2,19,22}$. According to Felisberti ${ }^{21}$, PHB blends may be considered biodegradable or partially biodegradable on basis of the biodegradation behavior of the combined polymer.

The blending of biodegradable polymers, such as starch and bioinert polymers, has received a considerable attention for possible applications in the waste disposal of plastics ${ }^{7,13,22-26}$. In the case of PHB based blends containing a bioinert polymer, a kind of biodeterioration may occur according to the morphology and surface properties of the samples. As a matter of fact, the microorganisms attack to the PHB part of the whole samples and provoke a disintegration of the samples by subtracting cementing material between separate synthetic regions ${ }^{22}$. However, it is worthy to mention that for some researchers, the total assimilation of the fragmentary products by the ecosystem is required if the polymers are to be acceptable from the ecological point of view ${ }^{13,27}$.

Several studies concerning the properties of LDPE/PHB blends have been performed and described in the literature ${ }^{2,4,5,15-18,28-36}$. There is evidence that LDPE/PHB blends are immiscible and form morphological structures with well distinguished phase boundaries between dispersed phase and matrix ${ }^{2,4,5,15-18,28-36}$. The morphological features of PHB/LDPE blends demonstrate the self-reinforced matrix where the minor component (PHB) forms the band-like fibrils embedded in the LDPE matrix. At the amount of PHB above $16 \%$, the blend system undergoes the morphology transfer from the oriented PHB structure to the isotropic one where the PHB fibrils transform into a network. The distinction between two morphologies reflects the different values of water permeability through the blend films ${ }^{18}$.

There are few papers published concerning the biodegradation properties of the LDPE/PHB blends. According to Martelli ${ }^{5}$ the literature for this type of blend is very modest mainly regarding blends of polyethylene/PHB without pro-oxidants. The utilization of these additives accelerates photo- and thermo-oxidation of synthetic polymers rendering the polyolefin based materials more susceptible to biodegradation ${ }^{2,5,6}$.

Get cheaper polymers with improvement of some desired properties is another relevant issue. Recently, a growing interest has been observed in the possibility of modifying polyolefins with fillers of natural origin, such as cereals, stems of plants, nut shells, cotton, cellulose, or wood flour, especially of the conifers ${ }^{1}$.

Castor bean (Ricinus communis L.) also known as castor oil bean is of great economic importance due to the oil extracted from its seeds. Castor oil has been used in various applications, such as raw materials for chemicals, cosmetics, lubricants and in biodiesel production ${ }^{37,38}$.

The oil extraction process for producing biodiesel and lubricant generates the castor bean cake as a residue, which is highly concentrated in proteins. Therefore, the valorization of this co-product should contribute to improve the productive chain of biodiesel ${ }^{37,38}$

Studies on the use of castor oil cake as raw material for ethanol production, as a protein source for the production of biodegradable materials and as a filler to obtain composite materials with improved properties have been described in the literature $37-41$.

The effect of the addition of a pressed castor oil cake, a biodiesel co-product, on the mechanical properties of a grade of LDPE used in the packaging industry was recently evaluated. It was verified that the addition of this filler to the LDPE matrix improves the flexural properties of this polymer $^{39}$

Patent application filed by a Brazilian oil industry and published recently requires the privilege of obtaining composite materials with enhanced degradability using castor oil cake as filler ${ }^{40}$. The description of this invention is not available yet.

According to our knowledge, there is a lack in literature regarding the properties of LDPE/PHB blends filled with castor oil cake. Therefore, the aim of this study is to evaluate the effect of the composition of these blends on their properties.

The design of experiments (DOE) technique provides an efficient means of optimizing the process as well as 
determining the optimal formulation of a specific mixture. The main distinction between mixture DOE and other types of DOE is that in the former, the input variables are non-negative proportionate amounts of mixture. If the relationship is expressed as fractions of the mixture the sum must be equal to one. Furthermore, in mixture DOE the measured response is assumed to depend only on the relative proportions of the components in the mixture ${ }^{16,42}$. In the first part of this study, the mixture design of experiments technique was applied in order to evaluate the effect of LDPE/PHB/CC mixtures composition on the mechanical properties. The samples biodegradation is under evaluation.

\section{Experimental Procedure}

\subsection{Material}

Low density polyethylene (LDPE, TS 0728), MFI $=2.20 \mathrm{~g} / 10 \mathrm{~min}-\mathrm{ASTM} \mathrm{D} 1238^{[43]}$, at $190{ }^{\circ} \mathrm{C}$ was donated by Petroquímica Triunfo (Brazil) and used as received. Poly (3-hydroxybutyrate) (PHB), $\mathrm{MFI}=16 \mathrm{~g} / 10 \mathrm{~min}-\mathrm{ASTM} \mathrm{D} 1238^{[43]}$, at $190{ }^{\circ} \mathrm{C}$ was obtained from PHB Industrial and used as received. The castor oil pressed cake (CC) was donated by Embrapa (Brazil). The material was detoxified by autoclaving at $120{ }^{\circ} \mathrm{C}$ for 30 minutes. After a drying process, the filler was ground in a ball mill and passed through a set of sieves with a decreasing mesh size. Only the powdered material with a size less or equal to $0.25 \mathrm{~mm}$ was used in this work. The composition of castor cake is shown in Table $1^{[16]}$.

\subsection{Mixture design of experiments}

In a mixture design of experiments the proportion of each component in the mixture may vary between zero and one and the sum of all components proportions should

Table 1. Chemical composition of the castor oil cake (\%).

\begin{tabular}{lc}
\hline Dry matter & 91.50 \\
Crude protein & 42.50 \\
Fibers & 20.04 \\
Calcium & 0.68 \\
Phosphorus & 0.78 \\
Ether extract & 4.23 \\
\hline
\end{tabular}

be equal to one. As a result, with three components the experimental region is a triangle defined by the points $(0,0,1),(0,1,0)$ and $(1,0,0)$. The vertices of the triangle correspond to mixtures containing $100 \%$ of one component and the sides of the triangle correspond to binary mixtures. The points lying in the interior of the triangle have some proportion of the three components.

In this work, the Minitab $15^{\mathrm{TM}{ }^{\circledR[44]}}$ software was used for planning the mixtures and it was also used for analyzing the mechanical behavior of the samples. Low density polyethylene, poly (3-hydroxybutyrate) and castor oil pressed cake were represented by the input variables designated as LDPE, PHB and CC, respectively. As it was desirable to consider the largest LDPE content in the ternary system, the components of the mixture were subjected to the following constraints: $0.7 \leq \mathrm{LDPE} \leq 1.0,0 \leq \mathrm{PHB} \leq 0.3$ and $0 \leq \mathrm{CC} \leq 0.3$. Figure 1 shows the design region of interest. The circles represent ten blends LDPE/PHB/CC that should be prepared to give an appropriate response surface using a polynomial equation of degree $n$.

The composition of the mixtures defined by the Minitab software $^{44}$ is presented in Table 2 .

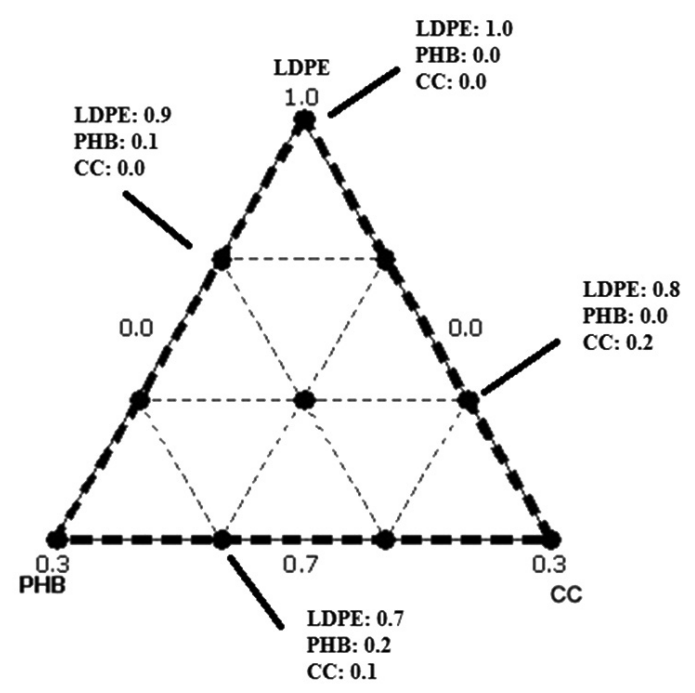

Figure 1. Simplex-lattice design region.

Table 2. Composition of LDPE/PHB/CC mixtures.

\begin{tabular}{|c|c|c|c|c|c|c|}
\hline \multirow{2}{*}{ Sample Code } & \multicolumn{2}{|c|}{ LDPE } & \multicolumn{2}{|c|}{ PHB } & \multicolumn{2}{|c|}{$\mathrm{CC}$} \\
\hline & $\%$ & grams & $\%$ & grams & $\%$ & grams \\
\hline 1 & 90 & 450 & 10 & 50 & 0 & 0 \\
\hline 2 & 80 & 400 & 0 & 0 & 20 & 100 \\
\hline 3 & 70 & 350 & 20 & 100 & 10 & 50 \\
\hline 4 & 80 & 400 & 10 & 50 & 10 & 50 \\
\hline 5 & 70 & 350 & 30 & 150 & 0 & 0 \\
\hline 6 & 80 & 400 & 20 & 100 & 0 & 0 \\
\hline 7 & 100 & 500 & 0 & 0 & 0 & 0 \\
\hline 8 & 70 & 350 & 10 & 50 & 20 & 100 \\
\hline 9 & 70 & 350 & 0 & 0 & 30 & 150 \\
\hline 10 & 90 & 450 & 0 & 0 & 10 & 50 \\
\hline
\end{tabular}




\subsection{Mixtures processing and characterization}

The LDPE/PHB/castor cake mixtures were prepared in a twin screw extruder (Extrusão Brasil- Model DRC) with $22 \mathrm{~mm}$ diameter screw extruder and a length to diameter $(\mathrm{L} / \mathrm{D})$ ratio equal to 36 at $100 \mathrm{rpm}$. The temperature profile in the extruder from the feed to the metering zone was set at $80 / 140 / 140 / 140 / 140{ }^{\circ} \mathrm{C}$. Tensile properties were measured using a Shimadzu Universal Testing Machine, Model AG-I with a $5 \mathrm{kN}$ load cell. Tests were conducted in accordance with ASTM D 638 ${ }^{[45]}$ using Type V test specimen dimensions. A crosshead speed of $10 \mathrm{~mm} / \mathrm{min}$ was employed. The flexural tests were carried on a Shimadzu Universal Testing Machine based on ASTM D-790 ${ }^{[46]}$. Tests were conducted at crosshead speed of $10 \mathrm{~mm} / \mathrm{min}$ at $23{ }^{\circ} \mathrm{C}$. Izod impact tests were performed using a $36.98 \mathrm{~N}$ pendulum on a Tinius-Olsen Impact Tester based on ASTM D-256 $6^{[47]}$. The morphology of the samples previously coated with gold was determined by scanning electron microscopy (Zeiss, DSM 960).

\section{Results and Discussion}

The mechanical properties of the different mixtures presented in Table 2 were evaluated through analysis of variance performed by the Minitab software ${ }^{44}$; some polynomial equations were tested in order to describe the mechanical behavior of the samples. The quadratic model in pseudo components (Equation 1) was selected because it was the most efficient from a statistical point of view (p-value $\leq 0.05$; coefficient of determination $\left(\mathrm{r}^{2}\right)$ close to 1 and variation inflation factor (VIF) values $<5)^{16,44}$, and it is given by:

$\mathrm{Y}_{\mathrm{i}}=\mathrm{b}_{1} \mathrm{X}_{1}+\mathrm{b}_{2} \mathrm{X}_{2+} \mathrm{b}_{3} \mathrm{X}_{3}+\mathrm{b}_{12} \mathrm{X}_{1} \mathrm{X}_{2+} \mathrm{b}_{13} \mathrm{X}_{1} \mathrm{X}_{3}+\mathrm{b}_{23} \mathrm{X}_{2} \mathrm{X}_{3}$

Where: $\mathrm{Y}_{\mathrm{i}}$ is the response variable; $\mathrm{b}_{1}, \mathrm{~b}_{2}, \mathrm{~b}_{3}, \mathrm{~b}_{12}, \mathrm{~b}_{13}$ and $b_{23}$ are the coefficients of the polynomial and $X_{1}, X_{2}$ and $X_{3}$ are the entrance variables. In this study $X_{1}, X_{2}$ and $\mathrm{X}_{3}$ represent the LDPE, PHB and CC proportions in the ternary mixtures.

The Equation 1 was used to generate the response surfaces presented in this work.

\subsection{Mechanical properties}

The response surface plot in Figure 2 shows a relationship between the Young's Modulus and the components proportion of LDPE/PHB/CC mixtures. It can be verified that higher values of Young`s Modulus (E) are obtained when increasing proportions of PHB are added to LDPE and its blends. LDPE is a flexible polymer $(\mathrm{E}=94 \mathrm{MPa})$, so this result was expected, as the PHB is a rigid polymer $(E=1031 \mathrm{MPa})$ with a low elongation at break $\left(\varepsilon_{\mathrm{b}}=3.1 \%\right)$. Similar result was found by Rosa and coworkers ${ }^{2}$.

The castor bean presents $50 \mathrm{wt} \%$ of fibers in its composition. A previous study ${ }^{39}$ demonstrated that the addition of CC to LDPE leads to an increase of LDPE tensile modulus and in the flexural properties. The response surface plot shows that addition of the castor oil pressed cake to LDPE leads to an increase of its elastic modulus. However, this effect is not as pronounced as the effect of the addition of PHB to polyethylene, especially in higher concentrations.

The results of this work indicate that, considering a fixed concentration of LDPE (70 wt \%), the partial replacement of PHB in ternary blends by CC leads to a decrease of the elastic modulus compared to those values presented by the LDPE/PHB binary blends.

The surface plot also shows that when the proportions of PHB and CC in the ternary mixtures tend to be similar there is no significant increasing of the Young's Modulus. According to $\mathrm{Machado}^{40}$, the addition of wood flour to PHB causes an increase of its elastic modulus. Therefore, our results suggest the PHB and CC interact in an antagonistic way tending to decrease the Young`s Modulus. However, it should be emphasized that a study about the effect of the addition of castor cake on the properties of PHB and a more detailed morphological study of the ternary blends should be performed in order to elucidate these results.

PHB has a tensile strength value (25.4 MPa) higher than the one presented by LDPE (12.2 MPa). However, the analysis of Figure 3 shows that the addition of PHB to LDPE

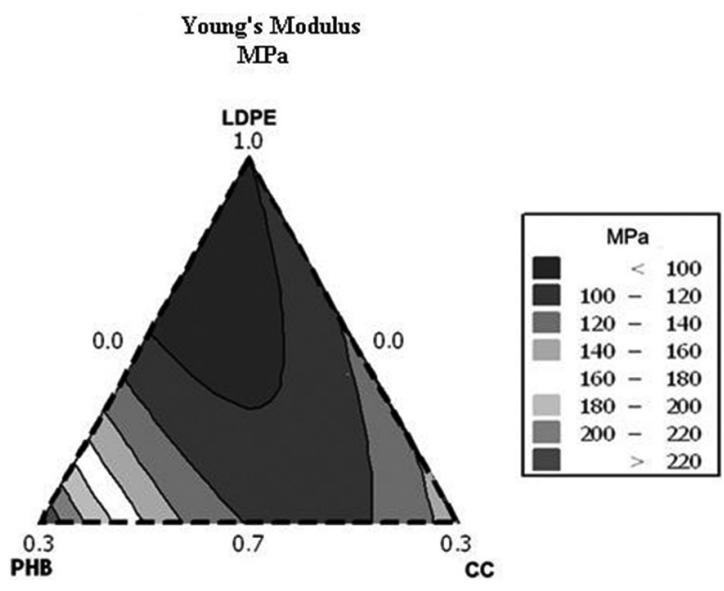

Figure 2. Response surface plot of Young`s modulus.

Tensile Strenght (MPa) LDPE

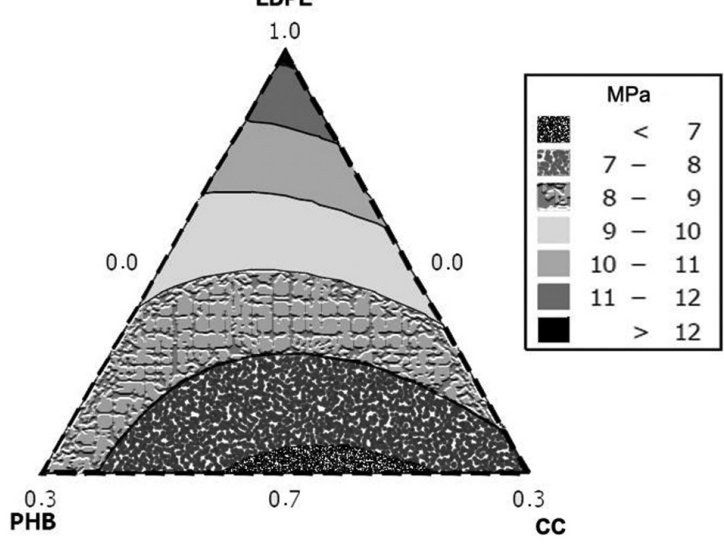

Figure 3. Response surface plot of tensile strength. 
causes a reduction in the strength of this polymer. This result may be attributed to the immiscibility of LDPE/PHB blends and the weak interfacial adhesion between the two polymers.

Similar result was found when the castor pressed cake was added to the $\mathrm{LDPE}^{39}$. The unsatisfactory dispersion of the filler in the polymer may be responsible for the loss of mechanical properties. Although the addition of PHB and CC leads to a decrease of LDPE tensile strength, the results obtained in this work show that the tensile strength values of LDPE/PHB and LDPE /CC binary mixtures lies in the range from 8.9 to $10 \mathrm{MPa}$. As some commercial grades of LDPE have values of strength mechanical in this range, it may be inferred that the addition of a certain amount of PHB or CC to LDPE may be considered as a possibility to obtain LDPE based materials with increased susceptibility to biodegradation.

Figure 3 also shows that the ternary mixtures presented low values of tensile strength. As the content of LDPE in the ternary blends decrease the loss of mechanical resistance becomes more accentuated. However, ternary mixtures with low proportion of PHB and CC have strength tensile values quite close to the ones presented by some commercial grades of LDPE.

The response surface plot in Figure 4 shows a relationship between the elongation at break and the components proportion of LDPE/PHB/CC blends. The

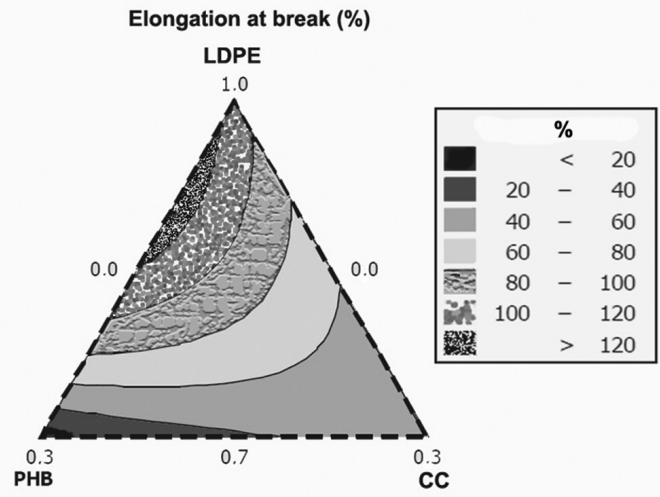

Figure 4. Response surface plot of elongation at break.

Table 3. Impact resistance values of LDPE and LDPE/PHB/CC mixtures.

\begin{tabular}{lcc}
\hline \multicolumn{1}{c}{ Samples } & J/m & $\begin{array}{c}\text { Standard } \\
\text { Deviation }\end{array}$ \\
\hline LDPE (100) & - & - \\
LDPE/PHB (90/10) & 311 & 21 \\
LDPE/PHB (80/20) & 187 & 19 \\
LDPE/PHB (70/30) & 37 & 4 \\
LDPE/CC (90/10) & 238 & 17 \\
LDPE/CC (80/20) & 134 & 7 \\
LDPE/CC (70/30) & 91 & 6 \\
LDPE/PHB/CC (80/10/10) & 193 & 9 \\
LDPE/PHB/CC (70/20/10) & 118 & 4 \\
LDPE/PHB/CC (70/10/20) & 132 & 8 \\
\hline
\end{tabular}

addition of higher concentration of PHB to LDPE gives rise to a decrease of elongation at break values. The elongation at break values of LDPE and PHB are $106.4 \%$ and $3.1 \%$, respectively. Therefore this result was expected. Figure 4 also shows that the addition of castor oil cake to LDPE causes a decrease of elongation at break lesser than the ones obtained through PHB addition especially in lower concentrations.

The elongation at break values obtained in this work also indicated that the addition of $10 \%$ of PHB to LDPE

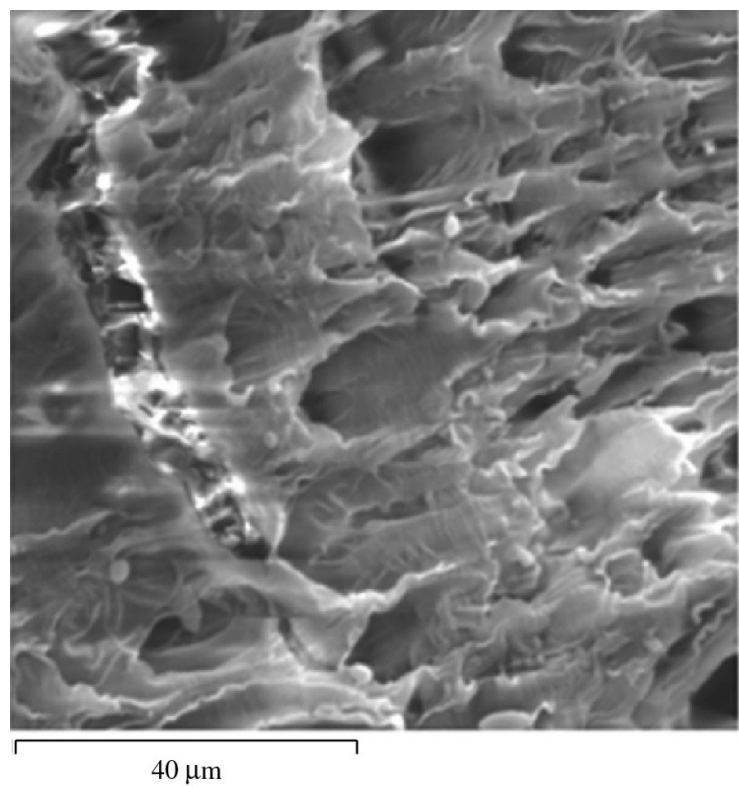

(a)

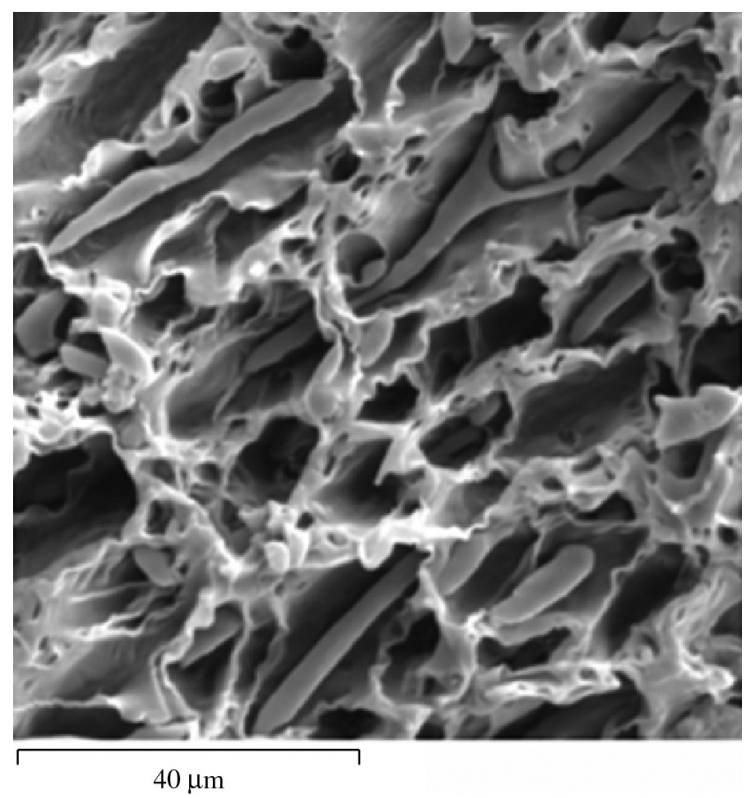

(b)

Figure 5. SEM micrographs of fractured surfaces of (a) $90 / 10$ LDPE/PHB blend (b) 80/20 LDPE/PHB blend. 
leads to an increase of LDPE elongation at break. This is an unexpected result. This composition should be studied in more depth. This result may be an indication that a tougher and flexible material can be obtained using this experimental condition.

The impact resistance values of LDPE and its mixtures with PHB and CC are presented in Table 3. The inspection of Table 3 shows that the impact resistance of LDPE decreases as the content of PHB and CC in the mixtures increases. This result may be attributed to the weak interfacial adhesion between the components of the mixtures and an unsatisfactory dispersion of the CC in the LDPE.

The analysis of data presented in Table 3 shows that the LDPE binary mixture containing $10 \%$ of PHB presents the highest value of impact resistance. Table 3 also shows that considering a fixed concentration of LDPE (70 wt $\%$ and $80 \mathrm{wt} \%$ ), the ternary mixtures have impact resistance higher than those presented by the corresponding binary mixtures. These results are in agreement with those derived from the determination of tensile properties. The values of Young's modulus and elongation at break obtained in this work show that adding increasing concentrations of PHB or CC to LDPE leads to the obtaining harder and more brittle materials.

The response surface plots of impact properties versus the components proportion of the LDPE mixtures were not obtained because it was not possible to obtain the impact resistance of LDPE in the experimental conditions used in this work.

The scanning electron microscopy was used for investigating the morphology of the mixtures. Figures $5 \mathrm{a}$ and $5 \mathrm{~b}$ present the micrographs of LDPE/PHB blends.

As the concentration of PHB in the blends increases there are significant differences in the morphology of the

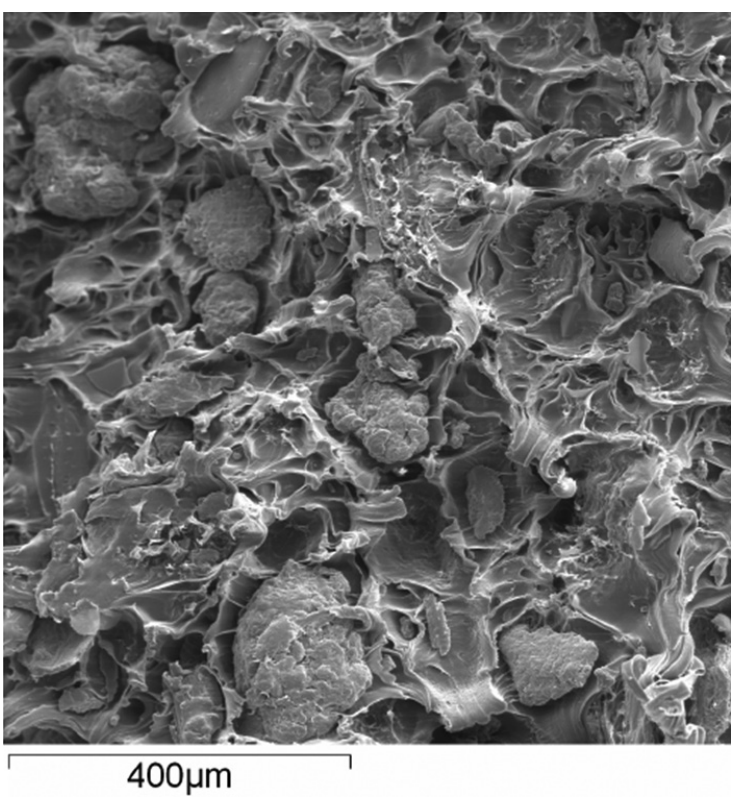

Figure 6. SEM micrograph of fractured surfaces of 90/10 LDPE/ CC mixture. blends. The micrograph of the blends containing $10 \%$ of PHB (Figure 5a) shows a ductile fracture process with PHB particles apparently loose and detached from LDPE. Information about the shape of the domains of PHB however could not be obtained from this micrograph because the particles may have been distorted by the process of fracture.

In the blend containing $20 \%$ of PHB (Figure 5 b) is possible to observe elongated particles of PHB dispersed in LDPE. The cylindrical forms can be derived from the flow

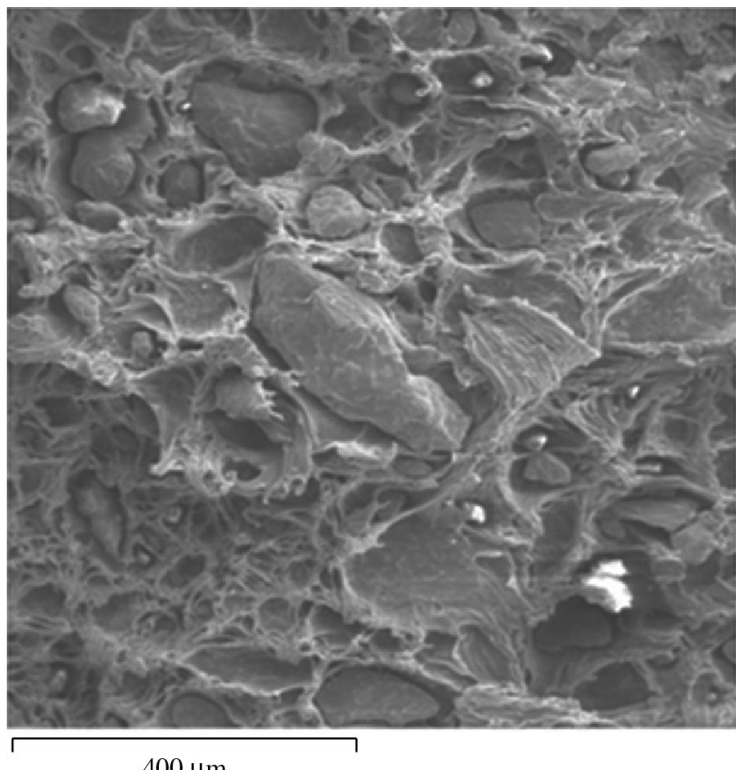

(a)

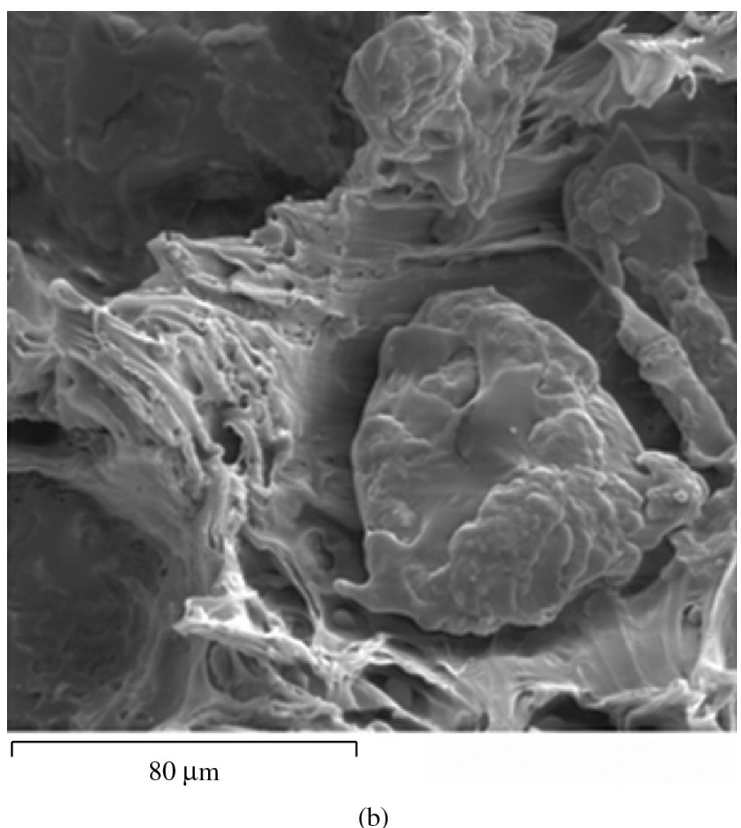

Figure 7. SEM micrographs of fractured surfaces of 80/10 LDPE/ PHB/10 CC mixture. 
caused by the impact energy. Anyway, the weak interfacial adhesion between LDPE and PHB is evident.

Figure 6 shows the morphology of the blend of LDPE containing $10 \%$ of CC. This micrograph appears quite different from that of blends containing $10 \%$ of PHB. The domains of castor pressed cake are quite visible and the fracture process does not seem to be so ductile. The weak interfacial adhesion is noticeable. Voids and cavities may be observed. Perhaps the tendency of LDPE/PHB blends present higher impact resistance values than those of LDPE/CC mixtures can be attributed to these morphological differences.

Figures $7 \mathrm{a}$ and $7 \mathrm{~b}$ present micrographs of the ternary mixture of LDPE containing $10 \%$ of PHB and $10 \%$ of CC. The micrographs clearly show the presence of smaller domains of PHB and larger domains of CC dispersed in LDPE. Agglomerates of CC are evident. The weak interfacial adhesion becomes visible by the presence of voids between the phases and the displacement of the particles of $\mathrm{CC}$ and $\mathrm{PHB}$.

\section{Conclusions}

1. Higher values of Young's Modulus (E) are obtained when increasing proportions of PHB or CC are added to the binary mixtures. The addition of PHB or CC leads to a decrease of LDPE tensile strength. However, the results obtained in this work show that the tensile strength values of LDPE/PHB and LDPE/CC binary mixtures lies in the range from 8.9 to $10 \mathrm{MPa}$. As some commercial grades of LDPE have values of strength mechanical in this range, it may be inferred that the addition of a certain amount of PHB or CC to LDPE leads to obtaining LDPE based materials with good performance and increased susceptibility to biodegradation.

2. As the content of LDPE in the ternary mixtures decreases, the loss of mechanical resistance becomes more accentuated. However, ternary mixtures with low proportion of PHB and CC have strength tensile values quite close to the ones presented by some commercial grades of LDPE.

3. The addition of PHB and castor oil cake to LDPE causes a decrease of LDPE elongation at break. However, the addition of $10 \%$ of PHB to LDPE leads to an increase of LDPE elongation at break. This unexpected result may be an indication that a tougher and flexible material can be obtained using this experimental condition.

4. The impact resistance of LDPE decreases as the content of PHB and $\mathrm{CC}$ in the blends increases. This result may be attributed to the weak interfacial adhesion between the components of the mixture and an unsatisfactory dispersion of the CC in the LDPE.

5. Significant differences in morphology of the LDPE/PHB blends were observed as the PHB concentration increased. The poor interfacial adhesion between the phases became visible in all samples. Similar information was also obtained from micrographs of the LDPE/PHB/CC samples.

\section{Acknowledgements}

The authors want to thank PHB Industrial, Braskem and Embrapa for donating the materials and CNPq for supporting this research.

\section{References}

1. Dziadur W and Tabor A. The effect of wood filler behavior on structure and fracture of polyethylene. Journal of Achievements in Materials and Manufacturing Engineering. 2006; 17(1-2):53-56.

2. Rosa DS, Gaboardi F, Guedes CGF and Calil MR. Influence of oxidized polyethylene wax (OPW) on the mechanical, thermal, morphological and biodegradation properties of PHB/LDPE blends. Journal of Materials and Science. 2007; 42:8093-8100. http://dx.doi.org/10.1007/s10853-007-1701-z

3. Arutchelvi J, Arkatkar A, Doble M, Bhaduri S and Uppara PS. Biodegradation of polyethylene and polypropylene. Indian Journal of Biotechnology. 2008; 7:9-22.

4. Martelli SM, Fernandes EG and Chiellini E. Thermal analysis of soil buried oxo-biodegradable polyethylene based blends. Journal of Thermal Analysis and Calorimetry. 2011; 5(3):333-339.

5. Martelli SM. Environmentally compatible polymeric blends and composites based on oxo-biodegradable polyethylene. [Dissertation]. Pisa: University of Pisa; 2011.

6. Falcone MB, Agnelli JAM and Faria LIL. Panorama setorial e perspectivas na área de polímeros biodegradáveis. Polímeros. 2007; 17(1):5-9. http://dx.doi.org/10.1590/S010414282007000100005

7. Shah PB, Bandopadhyay S and Bellare JR. Environmentally degradable starch filled low density polyethylene. Polymer Degradation and Stability. 1995; 47:165-173. http://dx.doi. org/10.1016/0141-3910(94)00088-P
8. Lucas N, Bienaime C, Belloy C, Queneudec M, Silvestre F and Nava-Saucedo J-M. Polymer biodegradation: Mechanisms and estimation techniques. Chemosphere. 2008; 429-442. PMid:18723204. http://dx.doi.org/10.1016/j. chemosphere.2008.06.064

9. Nowak B, Pajak J and Karcz J. Biodegradation of PreAged Modified Polyethylene Films. In: Scanning Electron Microscopy 32: Structure and properties of biodegradable polymer composites material. Vlascheslaw Kazmiruk; 2012. p. 643-670. Available from: <http:// www.intechopem.com./ books/scanning-electron-microscopy/biodegradation/of-preaged-modified-polyethylene-films $>$. Access in: 20/07/2013.

10. Coutinho FMB, Mello IL and Santa Maria LC. Polietileno: Principais tipos, propriedades e aplicações. Polímeros. 2003; 13(1):1-13. http://dx.doi.org/10.1590/S010414282003000100005

11. Hamad K, Kaseem M and Deri F. Melt rheology of poly (lactic acid)/low density polyethylene polymer blends. Advances in Chemical Engineering and Science. 2011; 1:208-214. http:// dx.doi.org/10.4236/aces.2011.14030

12. Negi H, Gupta S, Zaidi MGH and Goeli R. Studies on biodegradation of LDPE film in the presence of potential bacterial consortia enriched soil. Biologija. 2011; 57:141-147. http://dx.doi.org/10.6001/biologija.v57i4.1925

13. Arvanitotannis I, Biliaderis CG, Ogawa $\mathrm{H}$ and Kawasaki N. Biodegradable films made from low-density polyethylene (LDPE), rice starch and potato starch for food packaging applications: Part I. Carbohydrate Polymers. 1998; 36:89-104. http://dx.doi.org/10.1016/S0144-8617(98)00016-2 
14. Zheng Y, Yanful EK and Bassi AS. A review on plastic waste biodegradation. Critical Reviews in Biotechnology. 2005; 25:243-250. PMid:16419620. http:// dx.doi.org/10.1080/07388550500346359

15. Silva CR. Estudo de blendas potencialmente biodegradáveis de poli (3-hidroxibutirato) (PHB) e polietileno de baixa densidade. [Dissertation]. Campinas: Universidade Estadual de Campinas, 2001.

16. Burlein GAD. Avaliação das propriedades de polietileno de baixa densidade PEBD, poli (3-hidróxibutirato) (PHB) e de suas misturas com torta de mamona. [Dissertation]. Nova Friburgo: Universidade Estadual do Rio de Janeiro; 2010.

17. Arkatkar A, Arutchelvi J, Sudhakar M, Bhaduri S, Uppara PV and Doble M. Approaches to enhance the biodegradation of polyolefins. Open Environmental Engineering Journal. 2009; 2:68-80. http://dx.doi. org/10.2174/1874829500902010068

18. Pankova Y, Shchegolikhin A, Iordanskii A, Zhulkina A, Ol'khov A and Zaikov G. The characterization of novel biodegradable blends based on polihydroxybutyrate. Chemistry \& Chemical Technology. 2011; 5(3):333-339.

19. Sadi RK, Kurusu RS, Fechine GJM and Demarquette NR. Compatibilization of polypropylene/poly (3-hydroxybutyrate) blends. Journal of Applied Polymer Science. 2011; 123:35113519. http://dx.doi.org/10.1002/app.34853

20. Labuzek S, Nowak J and Pajak J. The susceptibility of polyethylene modified with bionolle to biodegradation by filamentous fungi. Polish Journal of Environmental Studies. 2004; 13(1):59-68.

21. Quental AC, Carvalho FP, Tada ES and Felisberti MI. Blendas de PHB e seus copolímeros: Miscibilidade e compatibilidade. Química Nova. 2010; 33(2):438-446. http://dx.doi.org/10.1590/ S0100-40422010000200035

22. Chandra R and Rustgi R. Biodegradable Polymers. Progress in Polymer Science. 1998; 23:1273-1335. http://dx.doi. org/10.1016/S0079-6700(97)00039-7

23. Sabetzadeh M, Bagheri R, Masoomi, M. Effect of corn starch content in thermoplastic starch/low density polyethylene blends on their mechanical and flow properties. Journal of Applied Polymer Science. 2012; 126:E-63-E-69. http://dx.doi. org/10.1002/app.36329

24. Pedroso AG and Rosa DS. Mechanical, thermal and morphological characterization of recycled LDPE/ corn starch blends. Carbohydrate Polymers. 2005; 59:1-9. http://dx.doi. org/10.1016/j.carbpol.2004.08.018

25. Ali RR, Rahman R, Kasmani RM, Ibrahim N, Mustapha SNH and Hasbullah H. Tapioca starch biocomposite for disposable packaging ware. Chemical Engineering Transactions. 2013; 32:1711-1716.

26. Hoque MdE, Ye TJ, Yong LC and Dahlan KZM. Sago-starch mixed with low density polyethylene biodegradable polymer: Synthesis and characterization. Journal of Materials. 2013; 1-7.

27. Avella M, Martuscelli E and Raimo M. Properties of blends and composites based on poly (3-hydroxy) butyrate (PHB) and poly (3-hydroxybutirate-hydroxyvalerate) (PHBV) copolymers. Journal of Materials Science. 2000; 35:523-545. http://dx.doi. org/10.1023/A:1004740522751

28. Lukanina JK, Khvatov AV, Kolesnikova NN and Popov AA. In: Progress in Chemical and Biochemical Physics, Kinectics and Thermodynamics 18: Structure and properties of biodegradable polymer composites material. Nova Science Publishers; 2008. p. 209-218.
29. Lopes VCP. Foto e biodegradação de PEBD, PHB e suas blendas. [Dissertation]. Rio Claro: Universidade Estadual Paulista; 2011.

30. Iordanskii AL, Kamaev PP, Ol'khov AA and Wasserman AR. Water transport in 'green' and 'petrochemical' polymers. Differences and similarities. Desalination. 1999; 26:139-145. http://dx.doi.org/10.1016/S0011-9164(99)00166-6

31. Kuriyama FL. Estudo das propriedades obtidas na blenda de PEBD (polietileno de baixa densidade) com PHB (polihidroxibutirato). [Monograph]. São Paulo: Faculdade de Tecnologia da Zona Leste; 2012.

32. Tertyshnaya YuV, Shibryaeva LS and Popov AA. Thermooxidative degradation of blends based on poly (3-hydroxybutyrate). Specifics of the process. Russian Journal of Physical Chemistry B. 2012; 6(1):38-41. http://dx.doi. org/10.1134/S1990793112010149

33. Ol'khov AA, Iordanskii AL, Zaikov GE, Shibryaeva LA, Litivinov IA and Vlasov SV. Morphologically special features of poly (3-hydroxybutyrate) / low density polyethylene blends. Polymer-Plastics Technology and Engineering. 2000; 39(5):783-792. http://dx.doi.org/10.1081/ PPT-100101403

34. Iordanskii AL, Ol'khov AA, Pankova YN, Bonartsev AP, Bonastseva GA and Popov VO. Hydrophilicity impact upon physical properties of the environmentally friendly poly (3-hydroxybutyrate) blends: Modification via blending. Macromolecular Symposia. 2006; 233:108-116. http://dx.doi. org/10.1002/masy.200690005

35. Bonartsev AP. Biosynthesis, biodegradation, and application of poly (3-hydroxybutyrate) and its copolymers - polyestersproduced by diazotrophic bacteria. Communicating Current Research and Educational Topics and Trends in Applied Microbiology. 2007; 295-307.

36. Shibryaeva LS, Iordanskii AL, Ol'kov AA and Zaikov GE. Thermal oxidation of self-degradable composite films based on LDPE. Oxidation Communications. 2005; 28(2):442-450.

37. Melo WC, Santos AS, Santa Anna LM and Pereira N Jr. Acid and enzymatic hydrolisis of the residue from Castor Bean (Ricinus cimmunis L.) oil extraction for ethanol production: detoxification and biodiesel process integration. Journal of Brazilian Chemical Society. 2008; 19(3):418-425. http://dx.doi. org/10.1590/S0103-50532008000300008

38. Lacerda RS, Bittante AMQB, Chambi H, Gomide, CA, Moraes ICF, Carvalho RA et al. Castor bean cake as raw material for biodegradable material. Available from: <http: www.icef11. org/contents/paper/fms/FMS174.pdf>. Access in: 02/05/2013.

39. Stork RR and Rocha MCGR. Composites of low density polyethylene and castor presscake. Polymer Plastics Technology and Engineering. 2010; 49(3):1352-1355. http:// dx.doi.org/10.1080/03602559.2010.496699

40. Machado ACOM, Ribeiro CMS, Freire DMG, Cunha LM, Castilho LR, Dias ML et al. Material compósito contendo material termoplástico e material protéico e processo de obtenção. BR PI0804101-6 A2; 2008 Sept 09, 2010 Jul 06. Available from: $<$ http://www.patentesonline.com.br/materialcomp-sito-contendo-material-termopl-stico-e-material-protico-e-processo-229188.html>. Access in: 04/10/2011.

41. Furtado RN, Carneiro MSS, Cândido MJD, Gomes FHT, Pereira ES, Pompeu RCFF et al. Valor nutritivo de dietas contendo torta de mamona submetida a métodos alternativos de destoxificação para ovinos. Arquivo Brasileiro de Medicina Veterinária e Zootecnia. 2012; 64(1):155-162. 
42. Barros B N ${ }^{\circ}$, Scarminio IS and Bruns RE. Como modelar misturas. In: Como fazer experimentos. 3rd ed. Campinas: Editora da UNICAMP; 2007. p. 367-400.

43. American Society for Testing and Materials - ASTM. ASTM D1238: Standard test method for melt flow rates of the thermoplastic by extrusion plastometer. Philadelphia: ASTM; 2010.

44. Minitab Inc. Minitab 15 software; 2007. Available from: $<$ http://www.minitab.com/er-Av/default.aspx >. Access in: 20/01/2012.
45. American Society for Testing and Materials - ASTM. ASTM D638: Standard test method for tensile properties of plastics. Philadelphia: ASTM; 2003.

46. American Society for Testing and Materials - ASTM. ASTM D790: Standard test methods for flexural properties of unreinforced and reinforced plastics and electrical insulating materials properties of plastics. Philadelphia: ASTM; 2003.

47. American Society for Testing and Materials - ASTM. ASTM D256: Standard test methods for determining the Izod pendulum impact resistance of plastics. Philadelphia: ASTM; 2000. 